\title{
Front Matter: Volume 9276
}

, "Front Matter: Volume 9276," Proc. SPIE 9276, Optical Metrology and Inspection for Industrial Applications III, 927601 (18 December 2014); doi: $10.1117 / 12.2181473$

SPIE. Event: SPIE/COS Photonics Asia, 2014, Beijing, China 


\title{
Optical Metrology and Inspection for Industrial Applications III
}

\author{
Sen Han \\ Toru Yoshizawa \\ Song Zhang \\ Editors
}

\section{9-11 October 2014 \\ Beijing, China \\ Sponsored by \\ SPIE \\ COS_Chinese Optical Society \\ Cooperating Organizations}

Tsinghua University (China) - Peking University (China) • University of Science and Technology of China (China) • Zhejiang University (China) • Tianjin University (China) • Beijing Institute of Technology (China) • Beijing University of Posts and Telecommunications (China) • Nankai University (China) • Changchun University of Science and Technology (China) • University of Shanghai for Science and Technology (China) • Capital Normal University (China) - Huazhong University of Science and Technology (China) • Beijing Jiaotong University (China) - Shanghai Institute of Optics and Fine Mechanics (China) - Changchun Institute of Optics and Fine Mechanics (China) - Institute of Semiconductors (China) - Institute of Optics and Electronics (China) • Institute of Physics (China) • Shanghai Institute of Technical Physics (China) • China Instrument and Control Society (China) - Optoelectronics Technology Committee, COS (China) • SPIE National Committee in China (China) • Optical Society of Japan (Japan) • Optical Society of Korea (Korea, Republic of) - The Australian Optical Society (Australia) - Optics and Photonics Society of Singapore (Singapore) • European Optical Society

Supporting Organizations

CAST_China Association for Science and Technology (China)

NSFC—National Nature Science Foundation (China)

Published by

SPIE

Volume 9276

Proceedings of SPIE 0277-786X, V. 9276

SPIE is an international society advancing an interdisciplinary approach to the science and application of light.

Optical Metrology and Inspection for Industrial Applications III, edited by Sen Han, Toru Yoshizawa, Song Zhang,

Proc. of SPIE Vol. 9276, 927601 - (c) 2014 SPIE · CCC code: 0277-786X/14/\$18 - doi: 10.1117/12.2181473 
The papers included in this volume were part of the technical conference cited on the cover and title page. Papers were selected and subject to review by the editors and conference program committee. Some conference presentations may not be available for publication. The papers published in these proceedings reflect the work and thoughts of the authors and are published herein as submitted. The publisher is not responsible for the validity of the information or for any outcomes resulting from reliance thereon.

Please use the following format to cite material from this book:

Author(s), "Title of Paper," in Optical Metrology and Inspection for Industrial Applications III, edited by Sen Han, Toru Yoshizawa, Song Zhang, Proceedings of SPIE Vol. 9276 (SPIE, Bellingham, WA, 2014) Article CID Number.

ISSN: 0277-786X

ISBN: 9781628413496

Published by

SPIE

P.O. Box 10, Bellingham, Washington 98227-0010 USA

Telephone +1 3606763290 (Pacific Time) · Fax +1 3606471445

SPIE.org

Copyright @ 2014, Society of Photo-Optical Instrumentation Engineers.

Copying of material in this book for internal or personal use, or for the internal or personal use of specific clients, beyond the fair use provisions granted by the U.S. Copyright Law is authorized by SPIE subject to payment of copying fees. The Transactional Reporting Service base fee for this volume is $\$ 18.00$ per article (or portion thereof), which should be paid directly to the Copyright Clearance Center (CCC), 222 Rosewood Drive, Danvers, MA 01923. Payment may also be made electronically through CCC Online at copyright.com. Other copying for republication, resale, advertising or promotion, or any form of systematic or multiple reproduction of any material in this book is prohibited except with permission in writing from the publisher. The CCC fee code is 0277-786X/14/\$18.00.

Printed in the United States of America.

Publication of record for individual papers is online in the SPIE Digital Library.

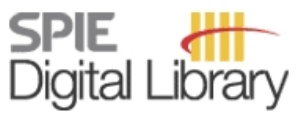

SPIEDigitalLibrary.org

Paper Numbering: Proceedings of SPIE follow an e-First publication model, with papers published first online and then in print and on CD-ROM. Papers are published as they are submitted and meet publication criteria. A unique, consistent, permanent citation identifier (CID) number is assigned to each article at the time of the first publication. Utilization of CIDs allows articles to be fully citable as soon as they are published online, and connects the same identifier to all online, print, and electronic versions of the publication. SPIE uses a six-digit CID article numbering system in which:

- The first four digits correspond to the SPIE volume number.

- The last two digits indicate publication order within the volume using a Base 36 numbering

system employing both numerals and letters. These two-number sets start with 00, 01, 02, 03, 04, $05,06,07,08,09,0 A, 0 B \ldots$. OZ, followed by 10-1Z, 20-2Z, etc.

The CID Number appears on each page of the manuscript. The complete citation is used on the first page, and an abbreviated version on subsequent pages. Numbers in the index correspond to the last two digits of the six-digit CID Number. 


\title{
Contents
}

\author{
vii Authors \\ ix Symposium Committees \\ xi Conference Committee \\ $\mathrm{xV}$ Introduction
}

\section{SESSION 1 OPTICAL METROLOGY METHODS I}

927602 Phase retrieval for optical metrology (Invited Paper) [9276-1]

927603 Single-shot three-dimensional shape measurement of specular surfaces by orthogonal color fringe pattern reflection technique [9276-9]

927604 Pixel correspondence calibration method of a 2CCD camera based on absolute phase calculation [9276-3]

927605 Matching method of the vision image captured by the lunar rover exploring on lunar surface $[9276-4]$

\section{SESSION 2 OPTICAL METROLOGY METHODS II}

927608 A high-reflective surface measurement method based on conoscopic holography technology [9276-7]

927609 Three-dimensional reconstruction of specular reflecting technical surfaces using structured light microscopy [9276-8]

$92760 \mathrm{~A}$ Optimized design of a TOF laser range finder based on time-correlated single-photon counting [9276-10]

\section{SESSION 3 OPTICAL METROLOGY METHODS III}

$92760 \mathrm{C}$ Optimizing binary dithering patterns to improve phase quality (Invited Paper) [9276-12]

9276 OD A hand-held, high-resolution 3D shape measurement system using structured and unstructured illumination [9276-13]

9276 OF Polarization scattering methods applied in particle analyzing [9276-15]

9276 OG Compact camera for 3D position registration of cancer in radiation treatment [9276-16] 
9276 Ol Real-time scanner error correction in white light interferometry (Invited Paper) [9276-18]

9276 OJ A robust automatic registration method for hand-held structured light 3D scanner [9276-19]

9276 OK System implementation of self-mixing interferometry technique-based measurement on Young's modulus [9276-20]

9276 OL Research on high-accuracy two-dimensional digital image correlation hardware measurement systems used in the engineering practice [9276-21]

$92760 \mathrm{M}$ The art of specifying surface quality (Invited Paper) [9276-22]

\section{SESSION 5 OPTICAL METROLOGY METHODS V}

9276 ON Dynamic 3D shape measurement based on grating projection and Fourier fringe analysis (Invited Paper) [9276-23]

$92760 Q \quad$ Comparing digital-light-processing (DLP) and liquid-crystal-display (LCD) projection technologies for high-quality 3D shape measurement (Invited Paper) [9276-26]

\section{SESSION 6 OPTICAL METROLOGY METHODS VI}

9276 OS Solutions on micro lens applied in multiple configuration systems [9276-28]

9276 OT The assessment of industrial CT's probing error [9276-29]

9276 OU A driving step auto-access method for single-wavelength microscopic interference [9276-30]

9276 OV Long-range active retroreflector to measure the rotational orientation in conjunction with a laser tracker [9276-31]

$92760 \mathrm{~W}$ Experimental study for the influence of surface characteristics on the fringe patterns (Invited Paper) [9276-32]

\section{SESSION 7 OPTICAL METROLOGY APPLICATIONS I}

9276 OY New method of verifying optical flat flatness [9276-34]

$92760 Z$ Mode-disturbing effect of laser speckle in optical fibers [9276-35]

927610 The model about the package structure of LED and the light intensity distribution [9276-36] 
927613 Effects of lens aberrations in phase space (Invited Paper) [9276-39]

927615 Optical fiber power measurement using different transfer standards [9276-41]

927617 A high accuracy subaperture stitching system for nonflatness measurement of wafer stage mirror [9276-43]

927619 A high speed camera with auto adjustable ROI for product's outline dimension measurement [9276-71]

POSTER SESSION

$92761 \mathrm{~A} \quad$ A registration method based on profile matching for vegetation canopy measurement [9276-2]

9276 1C Correction of refraction index based on adjacent pulse repetition interval lengths [9276-46]

9276 1D Accurate and automatic extrinsic calibration method for blade measurement system integrated by different optical sensors [9276-47]

9276 1G Analysis on how spectrum affects the test of solar cell electrical property [9276-50]

$92761 \mathrm{H} \quad$ A new technique of recognition for coded targets in optical 3D measurement [9276-51]

$927611 \quad$ Binocular videogrammetric system for three-dimensional measurement in low-speed wind tunnel [9276-52]

$92761 \mathrm{~J} \quad$ An improved bundle adjustment model and algorithm with novel block matrix partition method [9276-53]

$92761 \mathrm{~K} \quad$ High-speed three-dimensional shape measurement using spatial frequency encoding and DLP projector [9276-54]

$92761 \mathrm{~L} \quad$ Verification and analysis of stray light in high-power laser system [9276-55]

$92761 \mathrm{M}$ Cost-effective and full-field method for measuring vibration of loudspeaker membrane using fringe projection [9276-56]

9276 1N Optical image encryption in phase space [9276-57]

$927610 \quad$ Influence of both angle and position error of pentaprism on accuracy of pentaprism scanning system [9276-58]

$92761 \mathrm{P} \quad$ Optimal design of optical length in low turbidity measurement system with wavelength $1310 \mathrm{~nm}$ and $1550 \mathrm{~nm}$ [9276-59]

$92761 Q \quad$ The research of filtering on images with noises of the three-mirror aperture optical system [9276-60] 
9276 IR Measuring the displacement of the movable guard electrode in the new vertical calculable capacitor at NIM [9276-61]

9276 is Cramér-Rao analysis of three-channel phase diverse wave-front sensing for Golay3 aperture [9276-62]

9276 IT Dual-frequency laser displacement and angle interferometer [9276-63]

$92761 \mathrm{U}$ A 2-dimensionalal thickness measurement ellipsometer based on the liquid crystal variable retarder [9276-64]

9276 IW Precision judgment criteria and supplement data processing method in high-precision ranging with dual-comb lasers [9276-66]

9276 1X Novel high speed method using gray level vector modulation for 3D shape measurement [9276-67]

9276 IY A new usage of ASIFT for the range image registration [9276-68]

927612 A new geometrical model and mathematical method for three-dimensional surface reconstruction based on phase-shifting structured light technique [9276-69]

927620 An optimized FBG-based fatigue monitoring strategy on deepwater risers [9276-70]

927622 Hyperspectral visible-near infrared imaging for the detection of waxed rice [9276-73]

927623 Soluble solids content and firmness non-destructive inspection and varieties discrimination of apples based on visible near-infrared hyperspectral imaging [9276-74]

927624 Sensing driver's awareness by combining fisheye camera and Kinect [9276-75]

927625 High-frequency deformation grating fabrication techniques and applications [9276-76]

927626 Precision issues in angle measurements by means of autocollimator [9276-77] 


\section{Authors}

Numbers in the index correspond to the last two digits of the six-digit citation identifier (CID) article numbering system used in Proceedings of SPIE. The first four digits reflect the volume number. Base 36 numbering is employed for the last two digits and indicates the order of articles within the volume. Numbers start with 00, 01, 02, 03, 04, 05, 06, 07, 08, 09, OA, OB...0Z, followed by 10-1Z, 20-2Z, etc.

\author{
Aketagawa, Masato, $1 \mathrm{C}$ \\ Cao, Hui-bin, IP \\ Cao, YangYang, OA \\ Cen, Zhaofeng, $1 \mathrm{~L}$ \\ Chen, Dong, 01 \\ Chen, Guang, OL \\ Chen, Siwen, OT \\ Cheng, Xiaosheng, $1 \mathrm{H}$ \\ Cheng, $\mathrm{Xu}, 08,1 \mathrm{D}$ \\ Cui, Haihua, $1 \mathrm{H}$ \\ Dai, Fengzhao, 17 \\ Dai, Junfei, OC \\ Dai, Ning, $1 \mathrm{H}$ \\ Dai, Xianglu, 25 \\ Ding, Keqin, OL \\ Ding, Quanxin, OS \\ Dong, Hao, IW \\ Fan, Junliu, 1Q, is \\ Faridian, Ahmad, 02 \\ Feng, Qibo, OL \\ Filatov, Yuri V., 26 \\ Fu, Yuegang, OY \\ Gan, Haiyong, 15 \\ Gao, Jingjing, 19 \\ Gao, Peng, IM \\ Gao, Sitian, OT \\ Gong, Chen, $0 Q$ \\ Gu, Yonggang, 11 \\ Guan, Xin, OU \\ Gui, Hua-qiao, 0A, 1P \\ Guo, Changye, $1 \mathrm{H}$ \\ Guo, Fudong, 17 \\ Guo, Qinghua, OW \\ Guo, Zhenglai, OY \\ Han, Sen, OM, OY, 10 \\ He, Wantao, ID \\ $\mathrm{He}$, Yingwei, $1 \mathrm{G}$ \\ Hiratsuka, Shun, OG \\ Hofherr, O., OV \\ Hou, Zhiling, ON \\ Huang, LU, IR \\ Huang, PingXian, 1L \\ Huang, Shujun, 04 \\ Huang, Zhe, OA \\ Jiang, Hongzhi, $1 \mathrm{~A}$ \\ Jiang, $Y u, O Z$ \\ Jin, Hongzhen, $1 \mathrm{~K}$ \\ Jin, Yuan, $1 \mathrm{~L}$
}

Kamakura, Yoshihisa, OG
Ke, Jun, 19

Kettel, Johannes, 09

Larichev, Roman A., 26

Lei, Z., 24

Li, Beiwen, $0 Q$

Li, Da, OF

Li, Dong, IX, IY

Li, Dongsheng, OT

Li, Guowei, 13

Li, Haipeng, $1 \mathrm{G}$

Li, Huijun, OK

Li, Jian, 15

Li, Jianwei, 15

Li, Lichun, 05

Li, Mengyuan, 10

Li, Mingyang, 03

Li, Qi, OT

Li, Shi, OT

Li, Tongbao, $1 \mathrm{R}$

Li, Wei, OT

Li, Xiaotong, $1 \mathrm{~L}$

Li, Xuan, 20

Li, Xudong, $1 \mathrm{~A}$

Li, Xue, ON

Li, Xueyuan, OY

Li, Xunwu, is

Li, Yan, IT, IU

Li, Yang, IW

Li, Yanjie, 25

Li, Yong, 17

Li, Yong, 1K, 1M

Li, ZhongWei, 08, 0D, 0J, 1D, IJ

Liao, Yunjiang, $1 \mathrm{~A}$

Lin, Gui-Wen, $1 X$

Lin, Ke, OK

Liu, Chun-Yang, $1 Y$

Liu, Cuiling, OK

Liu, Dingpu, $1 G$

Liu, Hua, OS

Liu, Jian-guo, $1 \mathrm{P}$

Liu, Jun, IN

Liu, Xiuying, 1R

Liu, Yang, 1A

Liu, Yong, 03

Liu, Zhenghao, OK

Liv, Zhongyou, $1 \mathrm{R}$

Lu, Yunjun, 17

LU, Zhuliang, IR

Ma, Hui, OF 
Meng, Fangfang, $1 \mathrm{U}$

Meng, Haifeng, $1 \mathrm{G}$

Müller, Claas, 09, 0V

Nakamura, Katsumasa, OG

$\mathrm{Ni}$, Kai, $1 \mathrm{~W}$

Ning, D., 24

Novak, Matt, Ol

Osten, Wolfgang, 02

Ou, Jinping, 20

Pedrini, Giancarlo, 02

Qian, Jin, IR

Reinecke, Holger, 09, 0V

Ren, Peng, 20

Schmit, Joanna, 0 I

Shang, Desheng, 05

Shi, Chengying, $1 G$

Shi, YuSheng, 08, 0D, 0J, 1D

Shi, Yushu, OT

Singh, Alok Kumar, 02

Situ, Guohai, 13, 1N

Song, Xu, OT

Stover, John C., OM

Sun, Hao, OY

Sun, Haojie, 10

Sun, Jun, 05

Sun, Weimin, $\mathrm{OZ}$

Tang, Feng, 17

Tao, Wei, 12

Tian, Jin-Dong, $1 \mathrm{X}, 1 \mathrm{Y}$

Tu, Yanshuai, $1 \mathrm{~K}$

Wachten, C., OV

Wakayama, Toshitaka, OG

Wan, Wenhui, 05

Wan, Xiulong, 17

Wang, Congjun, OD

Wang, Huan-gin, OA, IP

Wang, Jian, 1K, $1 \mathrm{M}$

Wang, Jianbo, IR

Wang, Jie, $1 P$

Wang, Jun, 1Q, 1S

Wang, Qian, 19

Wang, Xiangzhao, 17

Wang, Xioahui, ON

Wang, Xuanze, OU

Wang, Youqing, $1 Q$

Wei, Dong, 1C

Wei, Haoyun, $1 T$

Wei, Ping, 19

Wei, Yifan, OW

Weng, Jinping, $1 \mathrm{H}$

Wu, Guanhao, IW

Wu, Mengqi, OJ

Wu, Quanying, 1N, 10, 1Q, 1S

Wu, Xuejian, $1 \mathrm{U}$

Wu, Yuxiang, 03

Wuhe, Z., 24

$X i$, Jiangtao, OK, OW

Xia, Zemin , 1J

Xiao, Suzhi, 12

Xie, Huimin, 25
Xu, Kun, 10

$\mathrm{XU}$, Liang, $1 \mathrm{G}$

$X U$, Mingfei, $1 W$

$\mathrm{Xu}, \mathrm{Nan}, 15$

$X U$, Xiaobin, $1 \mathrm{~N}$

$\mathrm{Xu}$, Yinghui, 05

Yan, Hao, $1 \mathrm{Z}$

Yan, Yunxiang, $\mathrm{OZ}$

Yang, Liangen, $\mathrm{OU}$

Yang, Yixin, $0 \mathrm{~A}$

$Y i$, Jingya, 03

Yin, Cong, IR

Yin, Yongkai, OW

Yoshizawa, Toru, OG

YU, Yanguang, OK, OW

Yue, Huimin, 03

Zeng, Maomao, OF

Zeng, Nan, OF

Zhai, Chao, 11

Zhai, Zhongsheng, OU

Zhan, Guomin, 08, 0J

Zhang, Dawei, 10

Zhang, Qican, ON

Zhang, Qiyuan, 10

Zhang, Song, OC, OQ

Zhang, Wei, 05

Zhang, Zhiliang, $1 \mathrm{M}$

Zhang, Zhixin, 15

Zhang, Zonghua, 04

Zhao, Can, 1D

Zhao, HengShuang, 08

Zhao, Hui, $1 \mathrm{Z}$

Zhao, Huijie, $1 \mathrm{~A}$

Zhao, Mantong, 22

Zhao, Shijie, IT

Zheng, Guoquan, 04

Zheng, Jianchao, 0 Z

Zhong, Kai, OD, OJ, 1D, 1J

Zhou, Fan, $1 \mathrm{G}$

Zhou, Jianliang, 05

Zhou, Liwei, OS

Zhou, Qian, IW

Zhou, Xiaohui, OD

Zhou, Yao, 23

Zhou, Zhi, 20

Zhu, Jianrong, OY

Zhu, Ye, 11

Zhuang, Jie, 10 


\title{
Symposium Committees
}

\author{
General Chairs
}

H. Philip Stahl, NASA Marshall Space Flight Center (USA)

Bingkun Zhou, Tsinghua University (China)

General Co-chairs

Arthur Chiou, National Yang-Ming University (Taiwan, China)

Jianlin Cao, China Ministry of Science and Technology (China)

Junhao Chu, Shanghai Institute of Technical Physics (China)

Technical Program Chairs

Songlin Zhuang, Shanghai University of Science and Technology (China)

Xingde Li, Johns Hopkins University (United States)

Technical Program Co-chairs

Qiming Wang, Institute of Semiconductors (China)

Xu Liu, Zhejiang University (China)

Daoyin Yu, Tianjin University (China)

Qihuang Gong, Peking University (China)

Tianchu Li, National Institute of Metrology (China)

Wei Huang, Nanjing University of Posts and Telecommunications (China)

Local Organizing Committee Chair

Guangcan Guo, University of Science and Technology of China (China) 
Local Organizing Committee Co-chairs

Guoqiang Ni, Beijing Institute of Technology (China)

Shusen Xie, Fujian Normal University (China)

Xiaomin Ren, Beijing University of Posts and Telecommunications (China)

Ying Gu, People's Liberation Army General Hospital (China)

Huilin Jiang, Changchun University of Science and Technology (China)

General Secretary

Qihuang Gong, Peking University (China)

Local Organizing Committee

Yan Li, Chinese Optical Society/Peking University (China)

Zhiping Zhou, Peking University (China)

Changhe Zhou, Shanghai Institute of Optics and Fine Mechanics (China)

Qingming Luo, Huazhong University of Science and Technology (China)

Chongxiu Yu, Beijing University of Posts and Telecommunications (China)

Hongda Chen, Institute of Semiconductors (China)

Yongtian Wang, Beijing Institute of Technology (China)

Yiping Cui, Southeast University (China)

Xuping Zhang, Nanjing University (China)

Feijun Song, Daheng Corporation (China)

Cunlin Zhang, Capital Normal University (China)

Yanting Lu, Nanjing University (China)

Yuejin Zhao, Beijing Institute of Technology (China)

Chunqing Gao, Beijing Institute of Technology (China)

Tiegen Liu, Tianjin University (China)

Xiaocong Yuan, Nankai University (China)

Weimin Chen, Chongqing University (China)

Zhongwei Fan, Academy of Optoelectronics (China)

Hanyi Zhang, Tsinghua University (China)

Lan Wu, Zhejiang University (China)

Yongsheng Zhang, University of Science and Technology of China (China)

Hong Yang, Peking University (China)

Xiaoying Li, Tianjin University (China)

Wei Xiong, Chinese Optical Society (China) 


\title{
Conference Committee
}

\author{
Conference Chairs
}

Sen Han, University of Shanghai for Science and Technology (China) and Suzhou H\&L Instruments LLC (China)

Toru Yoshizawa, Tokyo University of Agriculture and Technology (Japan) and 3D Associates (Japan)

Song Zhang, lowa State University (United States)

\section{Conference Program Committee}

Masato Aketagawa, Nagaoka University of Technology (Japan)

Yasuhiko Arai, Kansai University (Japan)

Xunde Bao, The University of Arizona (United States)

James H. Burge, College of Optical Sciences, The University of Arizona (United States)

Yuanshen Cao, National Institute of Measurement and Testing Technology (China)

Dong Chen, Bruker Nano Inc. (United States)

Jun Chen, Tokyo Polytechnic University (Japan)

Garrett D. Cole, Crystalline Mirror Solutions GmbH (Austria)

Yuegang Fu, Changchun University of Science and Technology (China)

Qingying Jim Hu, QUEST Integrated, Inc. (United States)

Zhihua Jiang, Shanghai Institute of Measurement and Testing Technology (China)

Kazuhide Kamiya, Toyama Prefectural University (Japan)

Katsuichi Kitagawa, Independent Consultant (Japan)

Malgorzata Kujawinska, Warsaw University of Technology (Poland)

Chao-Wen Liang, National Central University (Taiwan, China)

Yuxiang Lin, ASML (United States)

Yukitoshi Otani, Utsunomiya University (Japan)

Giancarlo Pedrini, Institut für Technische Optik (Germany)

Xiang Peng, Shenzhen University (China)

Kemao Qian, Nanyang Technological University (Singapore)

Guohai Situ, Shanghai Institute of Optics and Fine Mechanics (China)

H. Philip Stahl, NASA Marshall Space Flight Center (United States)

John C. Stover, The Scatter Works Inc. (United States)

Takamasa Suzuki, Niigata University (Japan)

Xiaodi Tan, Beijing Institute of Technology (China)

Toshitaka Wakayama, Saitama Medical University (Japan) 
Xiangzhao Wang, Shanghai Institute of Optics and Fine Mechanics (China)

Jiangtao Xi, University of Wollongong (Australia)

Lianxiang Yang, Oakland University (United States)

Dawei Zhang, University of Shanghai for Science and Technology

(China)

Hao Zhang, Tianjin University (China)

Heng Zhang, National Institute of Metrology (China)

Ping Zhong, Donghua University (China)

Ping Zhou, The University of Arizona (United States)

Weihu Zhou, Academy of Opto-Electronics (China)

\section{Session Chairs}

1 Optical Metrology Methods I

Giancarlo Pedrini, Institut für Technische Optik (Germany)

Sen Han, University of Shanghai for Science and Technology (China)

2 Optical Metrology Methods II

Toru Yoshizawa, Tokyo University of Agriculture and Technology

(Japan) and 3D Associates (Japan)

Weihu Zhou, Academy of Opto-Electronics (China)

3 Optical Metrology Methods III

Song Zhang, lowa State University (United States)

Yukitoshi Otani, Utsunomiya University (Japan)

4 Optical Metrology Methods IV

Weihu Zhou, Academy of Opto-Electronics (China)

Guohai Situ, Shanghai Institute of Optics and Fine Mechanics (China)

5 Optical Metrology Methods $\mathrm{V}$

Junfei Dai, Zhejiang University (China)

Giancarlo Pedrini, Institut für Technische Optik (Germany)

Xing Zhong, Changchun Institute of Optics, Fine Mechanics and Physics (China)

6 Optical Metrology Methods VI

Yukitoshi Otani, Utsunomiya University (Japan)

Song Zhang, lowa State University (United States)

Dong Chen, Bruker Nano Inc. (United States)

7 Optical Metrology Applications I

Dong Chen, Bruker Nano Inc. (United States)

Junfei Dai, Zhejiang University (China)

Guohai Situ, Shanghai Institute of Optics and Fine Mechanics (China) 
8 Optical Metrology Applications II

Xing Zhong, Changchun Institute of Optics, Fine Mechanics and Physics (China)

Toru Yoshizawa, Tokyo University of Agriculture and Technology

(Japan) and 3D Associates (Japan)

Chao-Wen Liang, National Central University (Taiwan, China)

Proc. of SPIE Vol. $9276927601-13$

Downloaded From: https://www.spiedigitallibrary.org/conference-proceedings-of-spie on 26 Apr 2023 Terms of Use: https://www.spiedigitallibrary.org/terms-of-use 
Proc. of SPIE Vol. 9276 927601-14

Downloaded From: https://www.spiedigitallibrary.org/conference-proceedings-of-spie on 26 Apr 2023 Terms of Use: https://www.spiedigitallibrary.org/terms-of-use 


\section{Introduction}

This is the proceedings of the conference on Optical Metrology and Inspection for Industrial Applications III that was held as part of SPIE/COS Photonics Asia (in Beijing, China, 9-11 October 2014). This conference focuses on methods, analysis, and applications of optical metrology and inspection that have been applied to various industries with a particular emphasis on the manufacturing industry. The field of optical metrology and inspection has rapidly grown to wide acceptance for many industrial applications. For example, the requirement from industry realized high-speed and downsized measurement systems, and advances in machine/robot vision have provided compact and smart camera systems, new lighting systems, and better ways of data transfer.

Non-contact methods based on optical imaging principles have been seen wide use in the mechanical engineering and electronics industry, and also made advances in traditional manufacturing areas such as automotive and aerospace manufacturing. These methods are also being used for defect and flaw inspection, and precision measurements. Recent computing power has made analysis methods such as phase-shifting a viable tool for fast on-line inspection for process control and metrology applications. This conference is intended to address the latest advances and future developments in the areas of optical metrology and inspection as they are applied to practical applications in various industries.

In these proceedings, papers submitted to the conference are presented in the following eight sessions: Optical Metrology Methods I to VI and Optical Metrology Applications I and II, and one Poster Session.

In addition to optical principles and techniques, imaging methods and analysis techniques have also become more and more popular in practical applications due to rapid advanced computational processing methods, camera systems and device technologies including various optoelectrical elements and devices. In the next conference scheduled in 2016, more papers are expected to be presented in those areas as well.

\section{Sen Han \\ Toru Yoshizawa \\ Song Zhang}


Proc. of SPIE Vol. 9276 927601-16

Downloaded From: https://www.spiedigitallibrary.org/conference-proceedings-of-spie on 26 Apr 2023 Terms of Use: https://www.spiedigitallibrary.org/terms-of-use 